Original Research Paper

\title{
PEMENUHAN HAK KESEHATAN BAGI NARAPIDANA DI RUMAH TAHANAN NEGARA KELAS II B KEBUMEN
}

\section{Dimas Darmawan}

\section{Prodi Teknik Pemasyarakatan, Politeknik Ilmu Pemasyarakatan}

Email Corresponding:
dimasdarmawan021@gmail.com
Page : $1-7$

\section{Kata Kunci :}

Hak Kesehatan,

Narapidana,

Kendala,

Solusi

Keywords:

Health Rights,

Prisoners,

Constraints,

Solutions
Narapidana adalah terpidana yang menjalani pidana hilang kemerdekaan di lembaga pemasyarakatan. Oleh karena itu Pemerintah melalui Direktorat Jenderal Pemasyarakatan wajib menjamin terpenuhinya hak-hak mereka yang lain, salah satunya adalah hak untuk mendapatkan pelayanan kesehatan yang optimal baik secara fisik, mental, spiritual maupun sosial. Penelitian ini bertujuan untuk mengetahui dan menjelaskan pemenuhan hak kesehatan bagi narapidana di Rumah Tahanan Negara Kelas II B Kebumen serta kendala apa saja yang muncul dalam pemenuhan hak kesehatan narapidana tersebut. Jenis penelitian ini adalah penelitian hukum dengan pendekatan yuridis empiris atau penelitian hukum sosiologis. Adapun teknik pengumpulan data dilakukan melalui penelitian lapangan dan kepustakaan dengan teknik analisis data kualitatif. Berdasarkan hasil penelitian diketahui bahwa pemenuhan hak kesehatan narapidana dilakukan dengan berpedoman pada peraturan perundang-undangan yang berlaku seperti pemberian penyuluhan kesehatan dan merujuk narapidana yang menderita sakit serius ke rumah sakit. Kemudian kendala yang muncul dalam pemenuhan hak kesehatan narapidana adalah keterbatasan tenaga kesehatan, minimnya sarana dan prasarana kesehatan, dan kondisi rutan yang mengalami overkapasitas. Solusinya adalah peningkatan kualitas dan kemampuan pegawai, serta penambahan fasilitas kesehatan dan ruang klinik yang memadai.

\section{ABSTRACT}

Prisoners are convicts who undergo the crime of missing independence in a penitentiary. Therefore, the Government through the Directorate General of Corrections must guarantee the fulfillment of their other rights, one of which is the right to obtain optimal health services both physically, mentally, spiritually and socially. This study aims to determine and explain the fulfillment of health rights for inmates in Kebumen State Class II B Detention Centers as well as any obstacles that arise in fulfilling the prisoners' health rights. This type of research is legal research with empirical juridical approach or sociological legal research. The data collection technique is done through field research and literature with qualitative data analysis techniques. Based on the results of the study, it is known that the fulfillment of prisoners' health rights is based on applicable laws and regulations such as providing health education and referring prisoners who are seriously ill to the hospital. Then the obstacles that arise in fulfilling prisoners' health rights are the limitations of health workers, the lack of health facilities and infrastructure, and the conditions of detention centers that are overcapsed. The solution is to improve the quality and ability of employees, as well as the addition of adequate health facilities and clinic space.

\section{PENDAHULUAN}

Dalam Pasal 1 Angka 7 Undang-Undang Nomor 12 Tahun 1995 tentang Pemasyarakatan dijelaskan bahwa yang dimaksud dengan Narapidana adalah terpidana yang menjalani pidana hilang kemerdekaan di lapas. Namun sebagai seorang yang sedang menjalani pidana, bukan berarti Narapidana kehilangan semua hak-haknya sebagai manusia atau bahkan tidak memperoleh hak apapun selama menjadi Narapidana. Hak dan kewajiban Narapidana ini telah di atur dalam 
sistem Pemasyarakatan, yaitu suatu sistem pemidanaan yang menggantikan sistem kepenjaraan ${ }^{1}$. Menurut Adi Sujatno yang pernah menjabat sebagai Direktur Jenderal Pemasyarakatan bahwa dengan beralihnya sistem kepenjaraan menjadi sistem pemasyarakatan dimana para narapidana diperlakukan lebih manusiawi dan dibina berdasarkan pancasila agar mereka sadar akan kesalahannya, memperbaiki diri, dan tidak mengulangi tindak pidana lagi sehingga dapat diterima kembali di lingkungan masyarakat. Dengan Sistem Pemasyarakatan yang di dalam nya ada konsep pendekatan pembinaan (treatment approach) diharapkan dapat mewujudkan perlindungan kepada narapidana dan hak-hak napi dalam menjalankan hukuman pidananya dengan bercirikan rehabilitative, korektif, edukatif, integrative ${ }^{2}$.

Bentuk nyata dari penerapan Sistem Pemasyarakatan yang ada di RUTAN (Rumah Tahanan Negara) adalah dengan dilaksanakannya perawatan dan pelayanan terhadap para tahanan atau narapidana. Hal ini dilakukan sebagai upaya untuk mencapai tujuan dari sistem pemasyarakatan yaitu terpenuhinya hak-hak dari narapidana yang sudah diatur didalam Undang-Undang No 12 Tahun 1995 tentang Pemasyarakatan tepatnya pada pasal 14 yang artinya juga memberikan kepastian hukum bagi para petugas pemasyarakatan yaitu mereka wajib untuk memberikan pelayanan seoptimal mungkin demi tercapainya tujuan pemasyarakatan. Hal ini sejalan dengan apa yang diungkapkan oleh Wayanamarshanti bahwa selama berada di dalam rutan, pemerintah wajib menjamin kebutuhan hidupnya seperti kebutuhan makan, perlengkapan untuk tidur, lingkungan yang bersih, dan pelayanan kesehatan yang optimal $^{3}$. Salah satu hak narapidana yang wajib diberikan adalah hak kesehatan, dimana hak kesehatan ini termasuk ke dalam hak-hak dasar atau fundamental dari setiap manusia. Pelayanan kesehatan terhadap narapidana ini harus dilakukan secara optimal tanpa memandang ras, agama, politik yang dianut serta keadaan ekonominya ${ }^{4}$. Mengenai teknis pelaksanaan pemenuhan kesehatan tersebut telah diatur di Pasal 21 Peraturan Pemerintah Nomor 58 Tahun 1999 tentang Syarat-syarat dan Tata Cara Pelaksanaan Wewenang, Tugas dan Tanggung Jawab Perawatan Tahanan. Dijelaskan bahwa setiap narapidana berhak memperoleh pelayanan kesehatan yang layak, disediakan poliklinik beserta fasilitasnya dan ditempatkan sekurang-kurangnya seorang dokter dan tenaga kesehatan lainnya.

Dalam Pasal 1 Angka 1 Undang-Undang Nomor 36 Tahun 2009 dijelaskan bahwa kesehatan adalah keadaan sehat, baik secara fisik, mental, spritual maupun sosial yang memungkinkan setiap orang untuk hidup produktif secara sosial dan ekonomis. Artinya sehat itu tidak hanya keadaan yang terbebas dari penyakit tetapi juga mencakup seluruh aspek kehidupan manusia seperti fisik, sosial, emosi, dan spiritual. Berdasarkan Keputusan Dirjen Pemasyarakatan Nomor PAS32.PK.01.07.01 Tahun 2016 tentang Standar Pelayanan Dasar Perawatan Kesehatan Di Lapas, Rutan, Bapas, LPKA dan LPAS dijelaskan bahwa pelayanan kesehatan dilakukan dalam 3 bentuk yaitu :

1. Pelayanan kesehatan promotif adalah suatu kegiatan dan/atau serangkaian kegiatan pelayanan kesehatan yang lebih mengutamakan kegiatan yang bersitat promosi kesehatan.

2. Pelayanan kesehatan preventif adalah suatu kegiatan pencegahan terhadap suatu masalah kesehatan/penyakit.

3. Pelayanan kesehatan kuratif adalah suatu kegiatan dan/atau serangkaian kegiatan pengobatan yang ditujukan untuk penyembuhan penyakit, pengurangan penderitaan akibat penyakit, pengendalian penyakit, atau pengendalian kecacatan agar kualitas penderita dapat terjaga seoptimal mungkin. 
Berpedoman pada pelayanan kesehatan yang diberikan di Lapas dan Rutan ialah merupakan suatu wujud pemberian Ham oleh Negara dalam konteks ini kepada warga nya. Adapun penyelenggaraan pelayanan kesehatan di Lapas di muat dalam beberapa peraturan perundangan diantaranya ${ }^{2}$ :

1. UU No 39 Tahun 1999 tentang HAM

2. UU No 12 tahun 1995 tentang Pemasyarakatan.

3. PP No 58 tahun 1999 tentang syaratsyarat dan Tata Cara Pelaksanaan Wewenang, Tugas dan Tanggung Jawab Perawatan Tahanan.

4. Permenkumham Nomor M.HH01.PK.07.02 Tahun 2009 Tentang Pedoman Penyelenggaraan Makanan Bagi Warga Binaan Pemasyarakatan di Lembaga Pemasyarakatan dan Rumah Tahanan Negara.

5. Permenkumham No M.HH-172.PL.02.03

Tahun 2011 tentang Pedoman Pengadaan Bahan Makanan Bagi Narapidana, Tahanan, dan Anak Didik Pemasyarakatan pada Lembaga Pemasyarakatan dan Rumah Tahanan Negara di Lingkungan Kemenkumham.

Kondisi rutan hampir di seluruh Indonesia yang mengalami overkapasitas tentunya akan menjadi salah satu kendala dalam upaya pemenuhan hak kesehatan narapidana. Hal ini juga berdampak kepada keterbatasan tenaga kesehatan dalam melakukan pelayanan kesehatan di rutan. Sehingga perlu adanya solusi yang dilakukan oleh pemerintah untuk mengatasi masalah tersebut.

Penelitian ini bertujuan untuk menganalisis bagaimana upaya pemenuhan hak kesehatan yang dilakukan terhadap narapidana di Rumah Tahanan Negara Kelas II B Kebumen serta kendala-kendala apa saja yang muncul dalam pemenuhan hak kesehatan narapidana tersebut sehingga dapat dicari solusi yang tepat untuk mengatasi kendala tersebut sehingga pelayanan kesehatan dapat dilakukan secara optimal.

\section{BAHAN DAN CARA}

Jenis penelitian yang digunakan adalah penelitian hukum dengan pendekatan yuridis empiris atau penelitian hukum sosiologis yang digunakan untuk memecahkan masalah penelitian melalui penelitian data primer di lapangan dimana sebelumnya dilakukan penelitian data sekundernya ${ }^{5}$. Data diperoleh melalui penelitian yang dilakukan di Rumah Tahanan Negara Kelas II B Kebumen.

Adapun teknik pengumpulan data dilakukaan melalui penelitian lapangan dan kepustakaan dimana penelitian lapangan dilakukan melalui wawancara dengan responden maupun informan untuk memperoleh data primer sedangkan penelitian kepustakaan dilakukan dengan menelaah peraturan perundang-undangan, mempelajari buku dan karya tulis yang relevan dengan penelitian yang diteliti untuk memperoleh data sekunder. Kemudian diidentifikasi, diolah, dan dianalisis secara sistematis dengan mengolah data menggunakan teknik analisis data kualitatif.

\section{HASIL}

Narapidana pada hakikatnya memiliki hak yang sama dengan masyarakat yang lain yang membedakan bahwa narapidana dibatasi hak kemerdekaan bergeraknya karena mereka harus hidup di dalam penjara yang dikelilingi oleh tembok tinggi. Salah satu hak narapidana adalah terkait dengan pelayanan kesehatan yang merupakan bagian dari pelayanan dan pembinaan terhadap narapidana untuk mempersiapkan mereka kembali ke lingkungan masyarakat. Hak kesehatan narapidana ini secara khusus telah diatur dalam Pasal 14 Undang-Undang Nomor 12 Tahun 1995 tentang Pemasyarakatan yang menyatakan bahwa narapidana berhak mendapatkan pelayanan kesehatan dan makanan yang layak. Menurut Prof.Dr. H.JJ. 
Leenen yang dimaksud pelayanan kesehatan adalah suatu keseluruhan dari aktivitasaktivitas professional dibidang pelayanan kuratif bagi manusia, atau aktivitas medis untuk kepentingan orang lain dan untuk kepentingan pencegahan ${ }^{6}$.

Berdasarkan hasil observasi yang dilakukan di Rumah Tahanan Negara Kelas II B Kebumen, pelayanan kesehatan dilakukan dengan berpedoman pada peraturan perundang-undangan yang berlaku, seperti :

a. UU No 39 Tahun 1999 tentang HAM

b. UU No 12 tahun 1995 tentang Pemasyarakatan.

c. PP No 58 tahun 1999 tentang syaratsyarat dan Tata Cara Pelaksanaan Wewenang, Tugas dan Tanggung Jawab Perawatan Tahanan.

d. Permenkumham Nomor M.HH01.PK.07.02 Tahun 2009 Tentang Pedoman Penyelenggaraan Makanan Bagi Warga Binaan Pemasyarakatan di Lembaga Pemasyarakatan dan Rumah Tahanan Negara.

e. Permenkumham No M.HH-172.PL.02.03 Tahun 2011 tentang Pedoman Pengadaan Bahan Makanan Bagi Narapidana, Tahanan, dan Anak Didik Pemasyarakatan pada Lembaga Pemasyarakatan dan Rumah Tahanan Negara di Lingkungan Kemenkumham.

f. Peraturan Menteri Kehakiman RI No. M.04.UM.01.06 tahun 1983 tanggal 29 Desember tentang tata cara penempatan, Perawatan Tahanan dan Tata Tertib Rumah Tahanan Negara.

g. Keputusan Menteri Kehakiman No. M.02PK.04.10 tahun 1990 tanggal 10 April tentang Pola Pembinaan Tahanan.

h. Keputusan Bersama Menteri Kehakiman RI dan Menteri Kesehatan RI nomor: M.01UM.01.06 Tahun 1987 dan nomor: 65/Menkes/ SKB/II/1987 tentang Pembinaan Upaya Kesehatan Masyarakat di Rumah Tahanan Negara dan Lembaga Pemasyarakatan.

Berikut beberapa kegiatan pelayanan kesehatan terhadap narapidana yang ada di Rumah Tahanan Negara Kelas II B Kebumen berdasarkan hasil observasi dan wawancara terhadap petugas kesehatan :

1. Pelayanan kesehatan bagi narapidana yang mengalami sakit.

2. Merujuk ke rumah sakit narapidana yang mengalami sakit serius.

3. Pelayanan kesehatan mental melalui sistem wali pemasyarakatan.

4. Pemberian makanan tambahan bagi narapidana yang sakit.

5. Layanan konsultasi kesehatan bagi narapidana.

6. Kerjasama dengan pihak ketiga untuk melakukan tes narkoba dan HIV/AIDS.

Dalam pelaksanan pelayanan kesehatan terhadap narapidana Rumah Tahanan Negara Kelas II B Kebumen masih mengalami kendala sehingga belum berjalan secara optimal. Kendala tersebut antara lain disebabkan kondisi rutan yang mengalami overkapasitas sehingga tenaga kesehatan yang ada kurang optimal dalam memberikan pelayanan. Kemudian adanya keterbatasan tenaga kesehatan karena disamping melakukan pelayanan kesehatan mereka juga ditugaskan untuk membantu mengecek barang bawaan kunjungan saat jam besuk narapidana sehingga pelayanan kesehatan berjalan kurang komfrehensif dan menyeluruh. Minimnya sarana dan prasarana kesehatan juga menjadi kendala di Rumah Tahanan Negara Kelas II B Kebumen seperti belum tersedianya mobil ambulance di klinik rutan padahal mobil ambulance untuk digunakan saat ada narapidana yang mengalami kondisi darurat yang harus segera dibawa ke rumah sakit.

Solusi yang dilakukan oleh pihak Rumah Tahanan Negara Kelas II B Kebumen untuk mengatasi kendala-kendala yang dialami 
dalam proses pelayanan kesehatan narapidana antara lain :

1. Melakukan kerjasama dengan Dinas Kesehatan Kabupaten Kebumen untuk membantu pelayanan kesehatan narapidana.

2. Melakukan penyuluhan kesehatan secara rutin setiap bulan kepada narapidana.

3. Menambah anggaran biaya untuk membeli sarana dan prasarana kesehatan.

4. Meningkatkan kualitas dan kemampuan petugas kesehatan melalui pelatihan dan pendidikan.

\section{PEMBAHASAN}

Pelayanan kesehatan terhadap narapidana harus dilakukan seoptimal mungkin karena sudah menjadi kewajiban pemerintah untuk melindungi hak-hak mereka. Adapun kegiatan-kegiatan yang perlu dilaksanakan dalam rangka pelayanan kesehatan narapidana mencakup aspek-aspek ${ }^{1}$ :

a. Promotif / upaya peningkatan kesehatan meliputi :

1) Peningkatan status gizi

2) Kebersihan perorangan

3) Olahraga untuk kesehatan

4) Penyuluhan kesehatan

b. Preventif/upaya pencegahan yang meliputi :

1) Isolasi / pengasingan

2) Pengendalian hewan pembawa penyakit

3) Kebersihan lingkungan

4) Pemeriksaan kesehatan berkala baik

5) fisik maupun mental

c. Kuratif / upaya penyembuhan yang meliputi :

1) Pengobatan dasar $P 3 K$

2) Pengobatan spesialistik (rujukan ke fasilitas pelayanan kesehatan

Dalam rangka kelancaran pelaksanaan program pelayanan kesehatan di Lapas dan Rutan , maka melalui Surat Keputusan Direktur Jenderal Pemasyarakatan Nomor : E.03.PP.02.10 Tahun 2003 telah ditetapkan standar pelayanan minimal pelayanan kesehatan dan makanan narapidana di Lapas dan Rutan sebagai berikut ${ }^{7}$ :

1. Secara melembaga pelayanan kesehatan yang ada masih dalam taraf sederhana yaitu pelayanan dokter dan klinik yang sifatnya pertolongan pertama.

2. Rujukan penderita dilakukan secara seadanya, tergantung kondisi pada masing-masing Lapas dan Rutan.

3. Bentuk-bentuk pelayanan promotif, preventif, kuratif dan rehabilitatif dilakukan secara sistematis.

Standar Pelayanan Minimal ini merupakan salah satu unsur pokok yang terdapat dalam pelayanan medis yang terdiri dari 3 macam yaitu ${ }^{8}$ :

1) Standar masukan, yaitu persyaratan minimal yang diperlukan untuk diselenggarakannya pelayanan medis yang bermutu. Unsur terpentingnya berupa tenaga pelaksana, sarana, dan dana

2) Standar Lingkungan, yang terpenting adalah garis besar kebijakan yang dipakai sebagai pedoman oleh sarana pelayanan dalam menyelenggarakan kegiatannya.

3) Standar Proses, dibedakan atas dua macam yaitu :

a) Tindakan medis diselenggarakan oleh sarana pelayanan.

b) Tindakan non medis yang diselenggarakan oleh sarana pelayanan.

Bentuk pelayanan kesehatan yang rutin dijalankan pihak Rumah Tahanan Negara Kelas II B Kebumen adalah dengan melakukan penyuluhan kesehatan kepada narapidana, untuk narapidana yang mengalami sakit bisa langsung menuju ke klinik untuk mendapatkan obat. Kemudian narapidana yang mengalami sakit berat atau dalam keadaan darurat akan langsung dirujuk ke rumah sakit umum. Terbatasnya tenaga kesehatan di rutan sangat berpengaruh terhadap proses pelayanan kesehatan karena hanya ada 2 petugas kesehatan saja. Kemudian terbatasnya sarana 
dan prasarana kesehatan seperti peralatan medis juga mengurangi kualitas pelayanan kesehatan narapidana. Seperti tidak adanya mobil ambulance sehingga narapidana yang mengalami kondisi darurat dibawa ke rumah sakit umum menggunakan mobil dinas rutan atau mobil pegawai. Ditambah lagi kondisi rutan yang mengalami overkapasitas sehingga memicu timbulnya berbagai penyakit bagi narapidana.

Kerjasama dengan instansi lain sangat perlu dilakukan sebagai solusi mengatasi kendala-kendala dalam pelayanan kesehatan narapidana. Rumah Tahanan Negara Kelas II B Kebumen melakukan kerjasama dengan Dinas Kesehatan Kabupaten untuk melakukan sosialisasi penyuluhan kesehatan dan juga tes urine terkait penggunaan narkoba secara rutin.

\section{KESIMPULAN DAN SARAN}

Berdasarkan uraian diatas penulis dapat menarik kesimpulan bahwa :

1. Pelaksanaan pelayanan kesehatan narapidana di Rumah Tahanan Negara Kelas II B Kebumen berpedoman kepada aturan perundang-undangan yang berlaku.

2. Salah satu bentuk kegiatan pelayanan kesehatan yang rutin dilakukan adalah melakukan penyuluhan kesehatan , untuk narapidana yang sakit langsung menuju klinik dan yang mengalami sakit berat maupun dalam keadaan darurat akan dirujuk ke rumah sakit umum.

3. Beberapa kendala yang dialami dalam proses pelayanan kesehatan adalah keterbatasan tenaga kesehatan, minimnya sarana dan prasarana kesehatan, dan kondisi rutan yang mengalami overkapasitas.

Untuk kegiatan penelitian selanjutnya penulis memberikan saran agar fokus kepada peningkatan sarana dan prasarana kesehatan dan klinik yang memadahi untuk pelayanan kesehatan narapidana.

\section{UCAPAN TERIMA KASIH}

Terima kasih peneliti ucapkan kepada seluruh pegawai Rumah Tahanan Negara Kelas II B Kebumen dan pihak-pihak terkait yang telah membantu proses penyelesaian penelitian.

\section{DAFTAR PUSTAKA}

1. Sinlae RA. Pemberian Hak Atas Pelayanan Kesehatan Bagi Narapidana yang Menderita Sakit Berat Di Lembaga Pemasyarakatan Kabupaten Dompu. Published online 2016.

2. Firmansyah R, A.Rani F, Adwani A. Pemenuhan Pelayanan Kesehatan dan Konsumsi Bagi Narapidana di Lapas dan Rutan. J Magister Huk Udayana (Udayana Master Law Journal). 2019;8(3):433. doi:10.24843/jmhu.2019.v08.i03.p10

3. Cristi N. Sumenda, Chreisye K. F. Mandagi FKK. Kajian Pelaksanaan Pelayanan Kesehatan Terhadap Narapidana di Klinik Rumah Tahanan Negara Kelas II B Kota Kotamobagu. Published online 2017:1-9.

4. Muhamad Sukron. Pelayanan Kesehatan Narapidana. Universitas Indonesia; 2009.

5. Gandhi Setyo Utomo. Perlindungan Hukum Terhadap Narapidana Atas Akses Kesehatan. 2017;(April 2017):978-979.

6. Leenen PDHJ, Drs. P.A.F. Lamintang, SH. Pelayanan Kesehatan Dan Hukum. Bina Cipta; 2015.

7. M Vesta D Napitupulu. Penegakan Hak Asasi Manusia Terhadap Pelayanan Kesehatan Narapidana di Lembaga Pemasyarakatan Kelas II A Manado. 2019;53(9):1689-1699. doi:10.1017/CBO9781107415324.004

8. A Azwar. Standar Pelayanan Medik, Materi Pelatihan Penerapan Standart Pelayanan Rumah Sakit, Medis Dan Pengawasan Etik.; 1994. 